\title{
Effect of Manufacturing Process of Master Alloy Powders on Homogeneity of Sintered Ti-5Al-1Fe by Blended Elemental Powder Metallurgy
}

\author{
Masashi Hayakawa, Hideki Fujii, Matsuhide Horikawa, Yosuke Inoue and Masahiro Morita
}

TOHO TITANIUM CO., LTD, Chigasaki-City Kanagawa, Japan

\begin{abstract}
$\underline{\text { Abstract }}$
To narrow down the candidates of the alloying element powders for Ti-5Al-1Fe products manufactured with BE/PM, two master alloy powders, atomized spherical $5 \mathrm{Al}-1 \mathrm{Fe}$ and crushed-andground polyhedron $5 \mathrm{Al}-1 \mathrm{Fe}-4 \mathrm{Ti}$ ternary powders, were investigated with emphasizing on homogeneity of alloying elements, $\mathrm{Al}$ and $\mathrm{Fe}$, in sintered Ti-5Al-1Fe. Intense $\mathrm{Al}$ segregation is recognized in the sintered specimen manufactured using $5 \mathrm{Al}-1 \mathrm{Fe}$ atomized powders, while strong segregation is not observed in the specimen manufactured using 5Al-1Fe-4Ti crushed-and-ground powders. Density of sintered specimen manufactured using $5 \mathrm{Al}-1 \mathrm{Fe}$ atomized powders is lower than that manufactured using $5 \mathrm{Al}-1 \mathrm{Fe}-4 \mathrm{Ti}$ crushed-and-ground powders. Al segregation and lower sintered density are probably caused by lower density of the powder substance, high flowability of spherical powders and phase constitutions some of which have low melting points. Those factors have to be taken into account to manufacture sintered titanium alloys with high homogeneity by BE/PM.
\end{abstract}

\section{Introduction}


Blended elemental powder metallurgy (BE/PM) is one of the near net shape (NNS) manufacturing methods in which pure titanium powders and alloying element (master alloy) powders are blended, compacted at room temperature and sintered at high temperature in vacuum. In this process, alloying process by mutual diffusion of $\mathrm{Ti}$ and alloying elements occurs during sintering, which contributes to reduction of the manufacturing cost in addition to the cost advantage of the near net shape process, compared to what is called the ingot metallurgy in which final products are obtained by heavy machining of the wrought materials converted from the melt ingots.

From the 1990s and later, from the viewpoints of cost reduction and high performance, various titanium alloys containing inexpensive elements, $\mathrm{Al}, \mathrm{Fe}, \mathrm{Cu}, \mathrm{O}, \mathrm{N}$ etc. as alloying elements were developed $^{(1-4)}$. Ti-5Al-1Fe is one of the alloys and currently became the most commonly used $\mathrm{a}+\mathrm{b}$ titanium alloy in Japan, which exhibits tensile properties equivalent to conventional Ti-6Al-4V. It has been actually applied to a wide range of application including sporting goods and automobile engine parts $^{(1-4)}$.

Considering those circumstances, employment of BE/PM for manufacturing NNS products made of Ti-5Al-1Fe may be beneficial to further reduce the manufacturing cost. However, to manufacture this alloy, the optimum method for the addition of allying elements has to be established.

There are a lot of candidates of powders to manufacture Ti-Al-Fe ternary alloys, for example, use of pure metal powders $(\mathrm{Al}$ and $\mathrm{Fe})$, binary alloy powders $\left(\mathrm{TiAl}, \mathrm{Al}_{3} \mathrm{Ti}, \mathrm{FeTi}\right)^{(5)(7)(8)}$ and ternary alloy powders ${ }^{(6-9)}$. However, homogeneity of alloying elements is sometimes an issue in BE/PM, in particular, when there are differences in powder size, shape and specific gravity between Ti powders and alloying element powders.

In this study, to narrow down the candidates of the alloying element powders for Ti-5Al-1Fe manufactured with BE/PM, two different master alloy powders, atomized spherical 5Al-1Fe and crushed-and-ground polyhedron $5 \mathrm{Al}-1 \mathrm{Fe}-4 \mathrm{Ti}$ ternary powders ${ }^{(9)}$, which was proposed as one of the preferable master alloys having good grindability and meltability in crucible, were investigated from the viewpoints of homogeneity of $\mathrm{Al}$ and $\mathrm{Fe}$ in the sintered products.

\section{Experimental procedures}

\subsection{Powders used}




\section{Pure titanium}

Pure titanium powders manufactured by hydrogenation and de-hydrogenation (HDH) process was used. Grain size range was from 45 to $150 \mu \mathrm{m}$, and D50 was $66 \mu \mathrm{m}$. Fe, O, N and C contents were $0.02,0.11,0.01$ and less than 0.01 mass $\%$, respectively.

Master alloy

Atomized master alloy powders of $5 \mathrm{Al}-1 \mathrm{Fe}$ was manufactured by the disc atomization method ${ }^{(10)}$ with which molten metal was dropped on the disk rotating at high speed and scattered droplets by centrifugal force were solidified to form spherical powders. After sieved with a sieve having $45 \mu \mathrm{m}$ opening, powders of $45 \mu \mathrm{m}$ or smaller were used. Chemical composition, D50 and true density are listed in Table 1. Ratio of Al and Fe contents was 4.47, which is slightly lower than the ideal value 5. However, it is affordable level. O content was very low, 0.038 mass $\%$ and true density $\left(2.73 \mathrm{~g} / \mathrm{cm}^{3}\right)$ was $40 \%$ lower than pure Ti. As shown in SEM image in Fig.1, the powders were fully spherical with few satellites.

Table 1 Chemical composition, grain size (D50) and real density of 5Al-1Fe atomized powders. D50 was measured with laser diffraction method.

\begin{tabular}{|c|c|c|c|c|c|}
\hline \multicolumn{3}{|c|}{ Confent (mass\%) } & \multirow{2}{*}{ ALFe } & \multirow{2}{*}{ DSO (م) } & \multirow{2}{*}{ Density $\left(\mathrm{gtcm}^{3}\right)$} \\
\hline A & Fe & $\mathbf{0}$ & & & \\
\hline 820 & 17.3 & D.05: & 4.74 & 36.5 & 273 \\
\hline
\end{tabular}




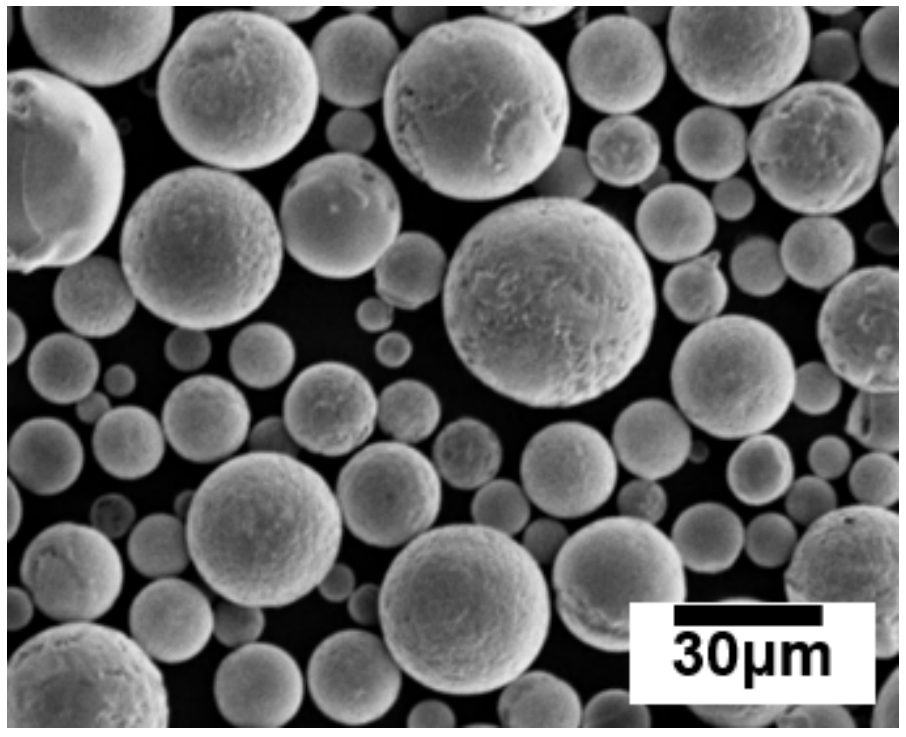

Fig. 1 SEM micrograph of 5Al-1Fe atomized powders.

5Al-1Fe-4Ti powders was manufactured by crushing and grinding melted ingots having the same composition. After sieved with a sieve having $45 \mu \mathrm{m}$ opening, powders of $45 \mu \mathrm{m}$ or smaller were used. Chemical composition, D50 and true density are listed in Table 2. Although O content was a little bit high, 0.476 mass $\%$, affection on $\mathrm{O}$ content in sintered specimens was small as explained later. Higher O content was probably caused by smaller particle size compared to the atomized powders and involvement of $40 \%$ Ti having strong affinity with $\mathrm{O}$. Ratio of $\mathrm{Al}$ and Fe contents was 4.91, which is close to the ideal value. True density was higher than $5 \mathrm{Al}-1 \mathrm{Fe}$ atomized powders although it was still lower than pure Ti powders. As shown in SEM image in Fig.2, the shape of the powders was polyhedron, which is similar to that of HDH pure Ti powders.

Table 2 Chemical composition, grain size (D50) and real density of 5Al-1Fe-4Ti powders manufactured by crushing and grinding melt ingots having the same composition. D50 was measured with laser diffraction method. 


\begin{tabular}{|c|c|c|c|c|c|}
\hline \multicolumn{3}{|c|}{ Content (nass } & \multirow{2}{*}{ ALFe } & \multirow{2}{*}{ DSO (ص) } & \multirow{2}{*}{ Density (gtcm } \\
\hline A & Fe & $\mathbf{0}$ & & & \\
\hline 48.9 & 9.95 & 0.476 & 4.91 & 11.5 & 3.72 \\
\hline
\end{tabular}

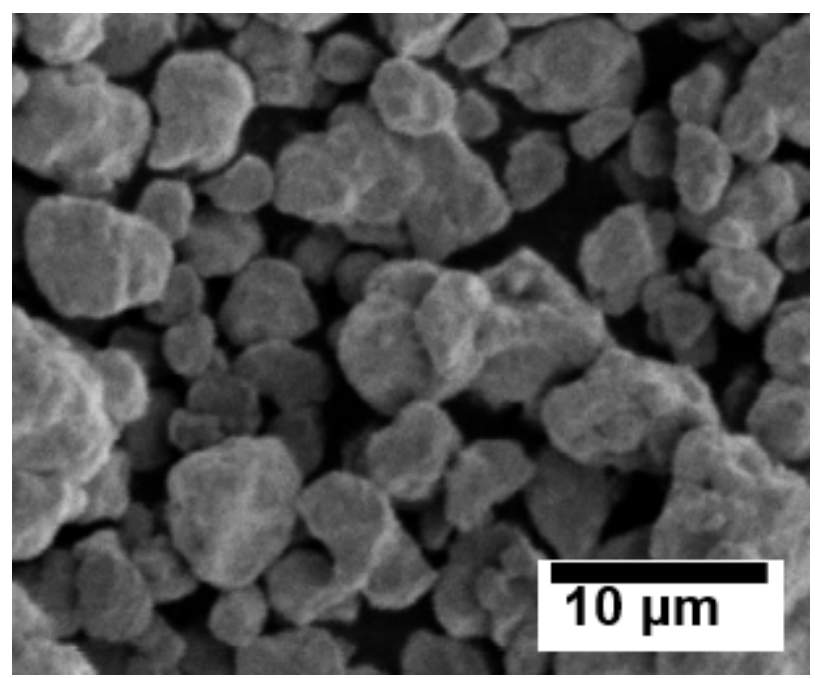

Fig. 2 SEM micrograph of 5Al-1Fe-4Ti powders manufactured by crushing and grinding route.

\subsection{Evaluation of master alloy powders}

The two master alloy powders were subjected to X-ray diffraction (XRD) and DTA analyses to investigate the phase constitution and liquid phase generation behaviors during heating to sintering temperature, both of which are considered to strongly affect the homogeneity and density of sintered materials. Heating and cooling rate employed in DTA analyses was $5{ }^{\circ} \mathrm{C} / \mathrm{min}$.

\subsection{Manufacturing of sintered Ti-5Al-1Fe}


Pure titanium powders and master alloy powders were blended to be the composition of 94Ti-5Al$1 \mathrm{Fe}$ (in mass ratio) and filled into elastic resin molds with cylindrical shape. After compaction by CIP at $490 \mathrm{MPa}$ pressure, cylindrical compacts of $15 \mathrm{~mm}$ in diameter and $100 \mathrm{~mm}$ in length were obtained. They were sintered in vacuum at $1250{ }^{\circ} \mathrm{C}$ for $2 \mathrm{~h}$.

\subsection{Evaluation for sintered Ti-5Al-1Fe}

Distribution of alloying elements, $\mathrm{Fe}$ and $\mathrm{Al}$, were analyzed for sintered cylindrical bars of $10 \mathrm{~mm}$ in length. Analyses were conducted for 5 portions approximately 0, 25, 50, 75 and $100 \mathrm{~mm}$ distant from top end of the bar, where powders were filled in the mold. EPMA analyses were also conducted to grasp more microscopic information on distributions of the alloying elements in the sintered materials.

Density was measured by Archimedes method. Optical microscope and SEM were used for microstructure observations.

\section{3. $\underline{\text { Results }}$}

\subsection{Characteristics of master alloy powder}

$\mathrm{XRD}$ pattern for $5 \mathrm{Al}-1 \mathrm{Fe}$ atomized powders is shown in Fig.3. Main phase of the powders was $\mathrm{Al}$ and three kinds of intermetallic compound $\left(\mathrm{FeAl}_{3}, \mathrm{Fe}_{5} \mathrm{Al}_{8}, \mathrm{Fe}_{\mathrm{X}} \mathrm{Al}_{(1-\mathrm{x})}\right)$ were involved.

Fig. 4 shows the result of DTA analysis for 5Al-1Fe atomized powders. Clear endothermic reaction occurred at $649{ }^{\circ} \mathrm{C}$, indicating the liquid phase generation at this temperature. The temperature is close to the melting point of $\mathrm{Al}$ and it is considered that $\mathrm{Al}$ alloy phase, which is the main phase in the powders and probably contains some amount of Fe in the form of solid solution, melted at around 649 ${ }^{\circ} \mathrm{C}$. 


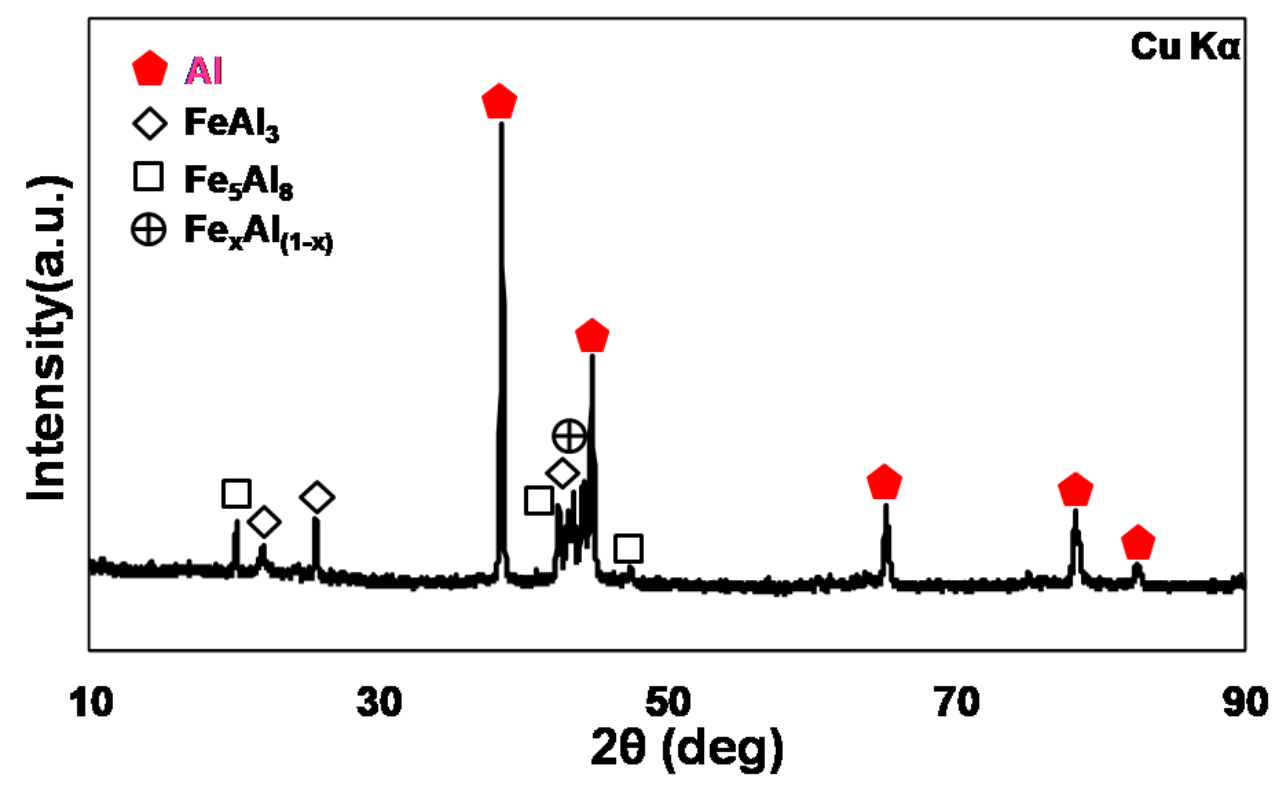

Fig. $3 \mathrm{X}$-ray diffraction pattern for 5Al-1Fe atomized powders. 


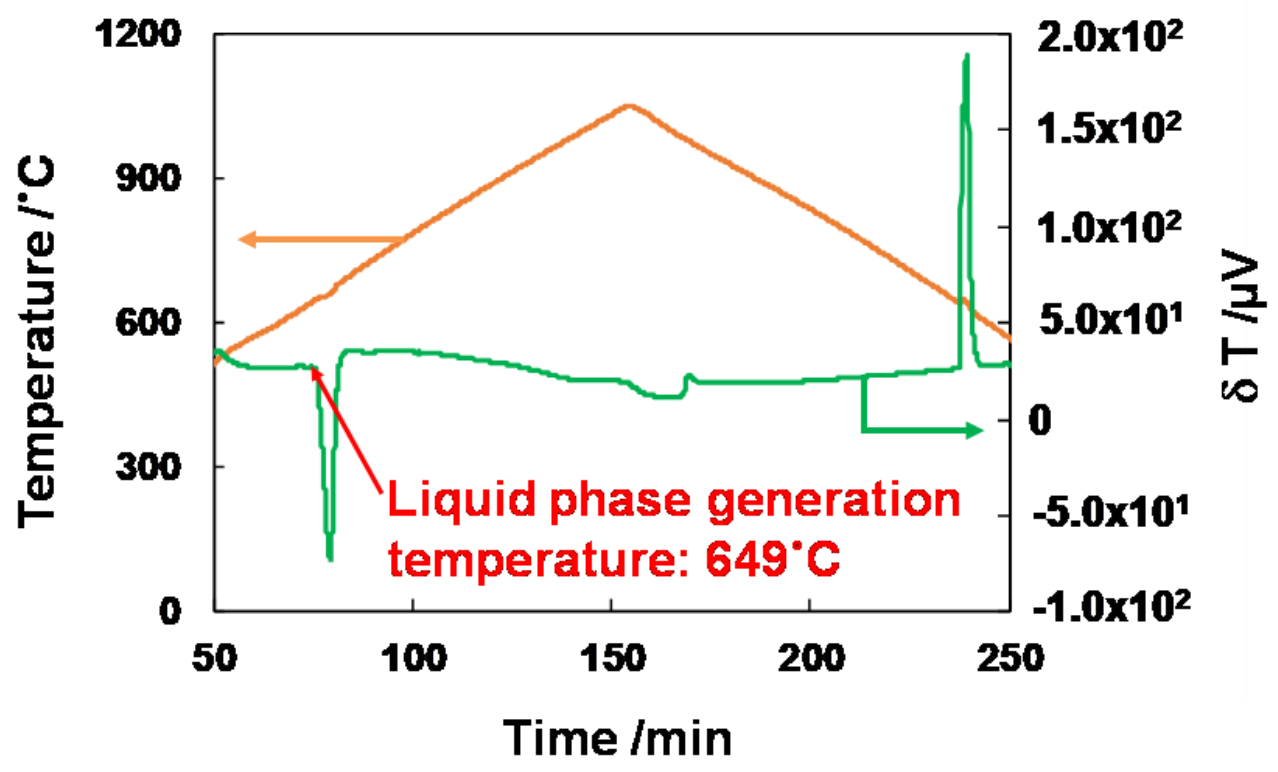

Fig. 4 DTA curve for 5Al-1Fe atomized powders.

Fig. 5 shows XRD pattern for 5Al-1Fe-4Ti crushed-and-ground powders. The powders were composed of $\operatorname{TiAl}_{(3-\mathrm{x})} \mathrm{Fe}_{\mathrm{X}}(\mathrm{X}=0.3)$ intermetallic compound and other phases were not recognized by XRD.

Figure 6 shows the result of DTA analysis for 5Al-1Fe-4Ti crushed-and-ground powders. DTA curve indicates that the liquid phase does not appear below the sintering temperature, $1250{ }^{\circ} \mathrm{C}$. 


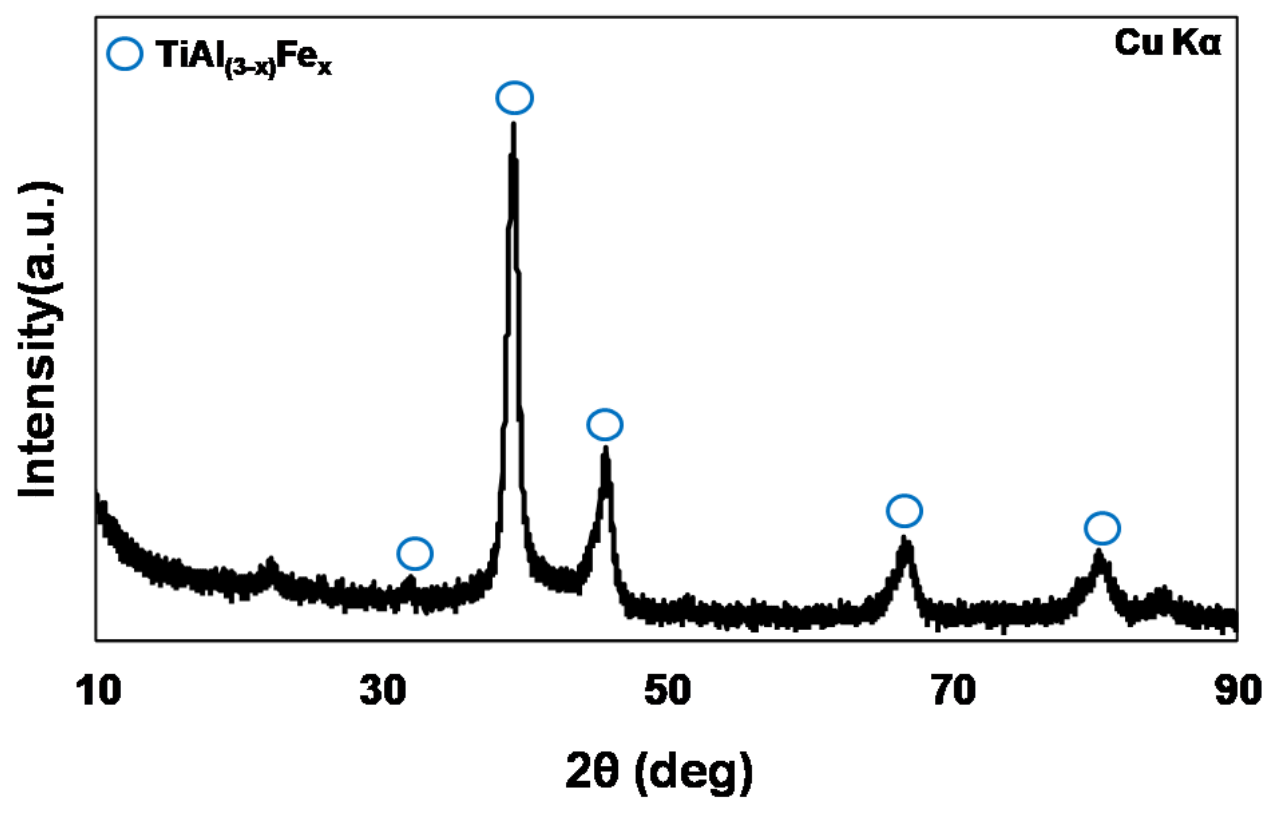

Fig 5 X-ray diffraction pattern for 5Al-1Fe-4Ti crushed-and-ground powders. 


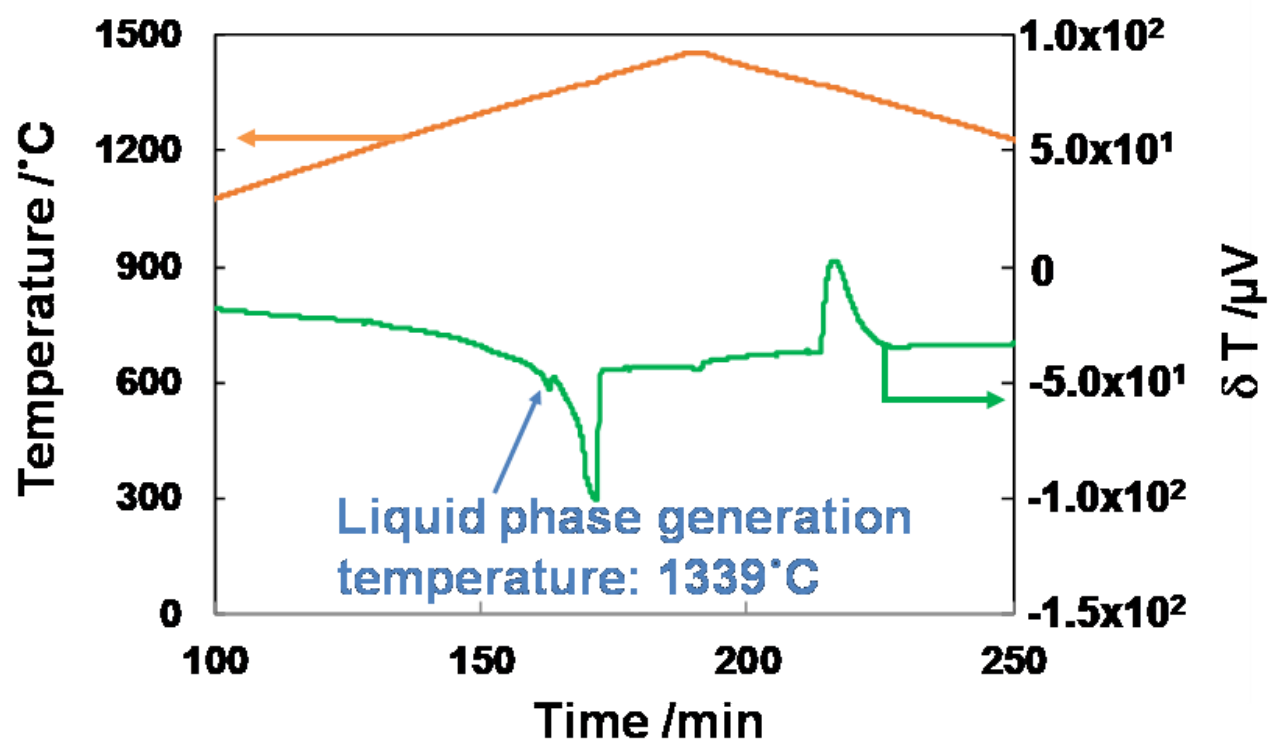

Fig 6 DTA curve for 5Al-1Fe-4Ti crushed-and-ground powders.

\subsection{Characteristics of sintered Ti-5Al-1Fe bar}

5Al-1Fe atomized powders

Chemical compositions of a sintered Ti-5Al-1Fe cylindrical bar manufactured using $5 \mathrm{Al}-1 \mathrm{Fe}$ atomized powders are shown in Table 3. Analyses were conducted for 5 portions indicated by T, MT, $\mathrm{M}, \mathrm{MB}$ and $\mathrm{B}$, which were explained in the table. While both $\mathrm{Fe}$ and $\mathrm{Al}$ contents were lower than the target ones in the portion $\mathrm{T}$, where powders were filled into the mold, they were close to the target ones in the other portions. The ratio of $\mathrm{Al}$ to Fe contents was 4.7 to 4.8 at every portion in the bar, a little bit lower than the target. O content was approximately 0.11 mass $\%$ in each portion.

Fig.7 shows $\mathrm{Al}$ and Fe distributions in the sintered Ti-5Al-1Fe cylindrical bar manufactured using $5 \mathrm{Al}-1 \mathrm{Fe}$ atomized powders. Although EPMA analyses were conducted for the cross section near 
fractured surface of a tensile test specimen, the results must show the actual Al and Fe distributions in the bar because the tensile test specimen was taken from a sintered cylindrical bar. As shown in Fig.7, strong segregation of Al was observed although Fe distributed homogeneously. Al content ranged from 3 to 5.5 mass $\%$, and both positive and negative segregation bands were created.

Density of the sintered bar manufactured using $5 \mathrm{Al}-1 \mathrm{Fe}$ atomized powders was $4.15 \mathrm{~g} / \mathrm{cm}^{3}$ and relative density was $93.9 \%$.

Optical microstructure of the sintered Ti-5Al-1Fe cylindrical bar manufactured using $5 \mathrm{Al}-1 \mathrm{Fe}$ atomized powders is shown in Fig.8. A lot of relatively large pores of approximately $30 \mu \mathrm{m}$ remained.

Table 3 Chemical compositions of various portions of sintered Ti-5Al-1Fe cylindrical bar of $15 \mathrm{~mm}$ in diameter and $100 \mathrm{~mm}$ in length, manufactured using $5 \mathrm{Al}-1 \mathrm{Fe}$ atomized powders. T, MT, M, MB and B indicate the analyzed portions approximately $0,25,50,75$ and $100 \mathrm{~mm}$ distant from one end of the bar, where powders were filled in the mold.

\begin{tabular}{|c|c|c|c|c|}
\hline \multirow{2}{*}{ Analysed portion } & \multicolumn{3}{|c|}{ Content (mass\%) } & \multirow{2}{*}{ AlFe } \\
\cline { 2 - 4 } & A & Fe & O & \\
\hline T & $\mathbf{3 . 8 7}$ & 0.81 & 0.112 & 4.77 \\
\hline UT & 4.29 & 0.90 & 0.111 & $4 . \pi$ \\
\hline UI & 4.39 & 0.93 & 0.110 & 4.72 \\
\hline B & 4.48 & 0.94 & 0.113 & $4 . \pi$ \\
\hline 4.43 & 0.94 & 0.114 & 4.71 \\
\hline
\end{tabular}




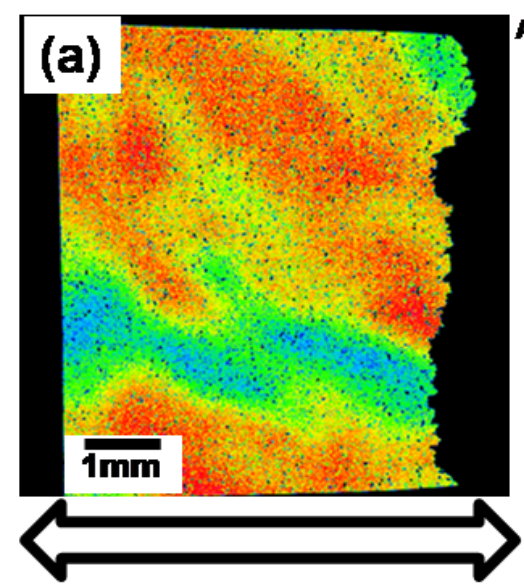

Longitudinal direction

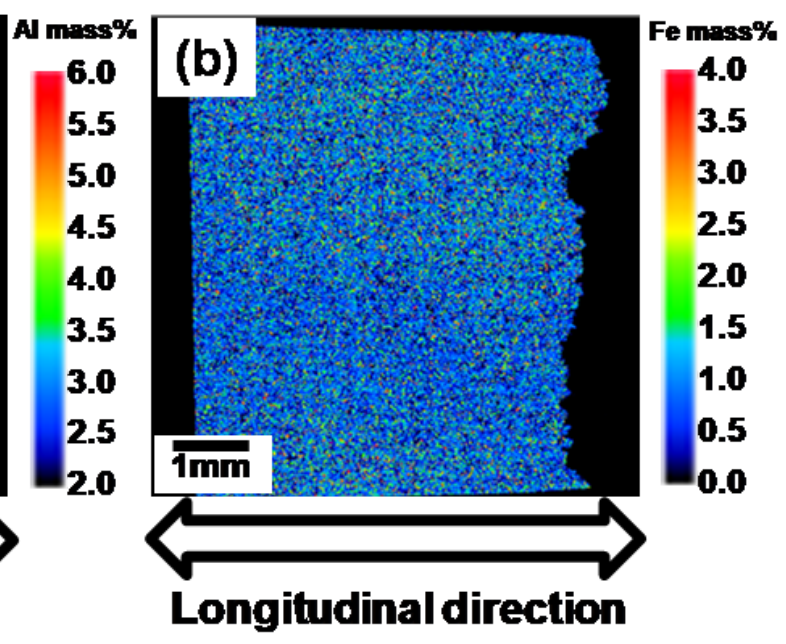

Fig. 7 (a) Al and (b) Fe distributions in sintered Ti-5Al-1Fe bar manufactured using 5Al-1Fe atomized powders. EPMA analyses were conducted for fractured tensile test specimen taken from sintered cylindrical bar.

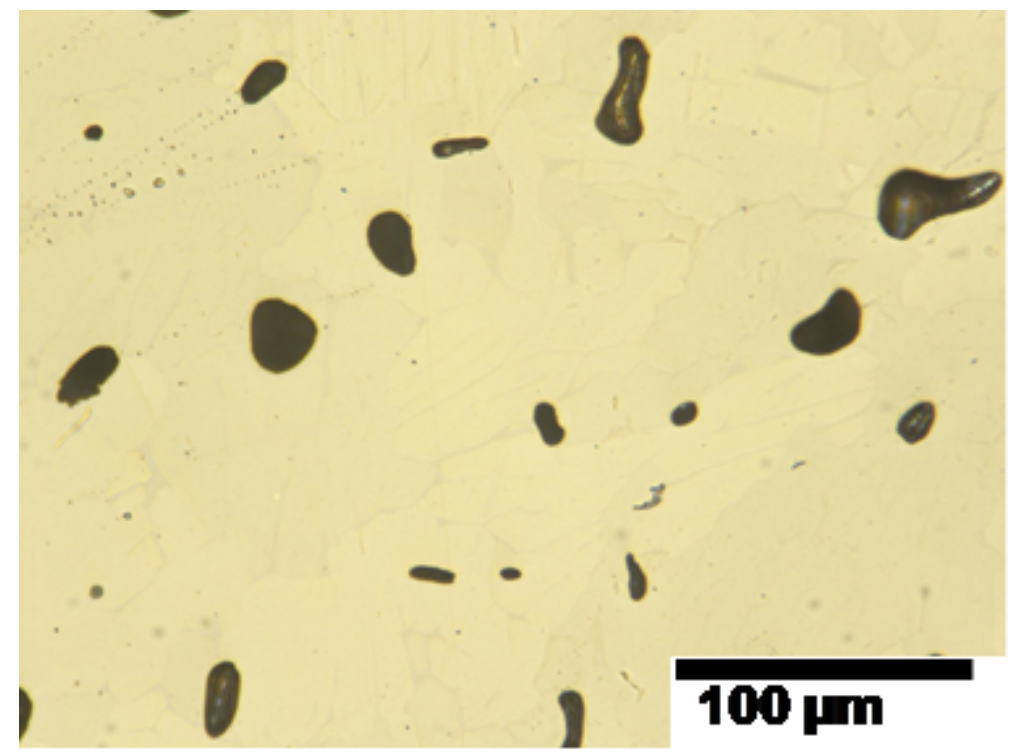


Fig 8 Optical micrograph of sintered Ti-5Al-1Fe bar manufactured using 5Al-1Fe atomized powders.

\section{Al-1Fe-4Ti crushed-and-ground powders}

Chemical compositions of a sintered Ti-5Al-1Fe cylindrical bar manufactured using 5Al-1Fe-4Ti crushed-and-ground powders are shown in Table 4. Analyses were conducted for 5 portions as conducted for the specimen manufactured using atomized master alloy powders. Both $\mathrm{Fe}$ and $\mathrm{Al}$ contents in any portions were almost the same and close to the target ones. The ratio of $\mathrm{Al}$ to $\mathrm{Fe}$ contents was 4.9 to 5.1 at every portion in the bar, and close to the target. O content was 0.15 to 0.16 mass $\%$ in each portion, slightly higher than that in the specimen manufactured using atomized master alloy powders. Slightly higher O content is probably caused by high O content in master alloy powders as shown in Table 2. However, This is almost the same as that in the wrought materials and considered to be an affordable level.

Fig. 9 shows $\mathrm{Al}$ and Fe distributions in the sintered Ti-5Al-1Fe cylindrical bar manufactured using $5 \mathrm{Al}-1 \mathrm{Fe}-4 \mathrm{Ti}$ crushed-and-ground powders. Just like the analyses for the specimen manufactured using the atomized master alloy powders (Fig.8), EPMA analyses were conducted for the cross section near fractured surface of a tensile test specimen. However, the results must show the actual $\mathrm{Al}$ and $\mathrm{Fe}$ distributions in the sintered bar. As shown in Fig.9, Al and Fe were homogeneously distributed in the specimen and significant segregation was not observed in the specimen manufactured using the crushed-and-ground master alloy powders (Fig.7).

Density of the sintered bar manufactured using 5Al-1Fe-4Ti crushed-and-ground powders was 4.39 $\mathrm{g} / \mathrm{cm}^{3}$ and relative density was $99.3 \%$, which is considerable higher than the specimen manufactured using the atomized master alloy powders.

Optical microstructure of the sintered bar manufactured using 5Al-1Fe-4Ti crushed-and-ground powders is shown in Fig.10. Reflecting high relative density, only a few small pores of several $\mu \mathrm{m}$ were observed.

Table 4 Chemical compositions of various portions of sintered Ti-5Al-1Fe cylindrical bar of $15 \mathrm{~mm}$ in diameter and $100 \mathrm{~mm}$ in length, manufactured using $5 \mathrm{Al}-1 \mathrm{Fe}-4 \mathrm{Ti}$ crushed-and-ground powders. Meaning of T, MT, M, MB and B are described in Table 3. 


\begin{tabular}{|c|c|c|c|c|}
\hline \multirow{2}{*}{ Analysed portion } & \multicolumn{3}{|c|}{ Content (mass\%) } & \multirow{2}{*}{ AlFe } \\
\cline { 2 - 4 } & A & Fe & O & \\
\hline T & 5.02 & 0.99 & 0.155 & 5.07 \\
\hline WT & 5.17 & 1.05 & 0.157 & 4.92 \\
\hline U & 5.09 & 1.04 & 0.151 & 4.89 \\
\hline B & 5.00 & 1.02 & 0.153 & 4.90 \\
\hline 4.78 & 0.98 & 0.163 & 4.88 \\
\hline
\end{tabular}

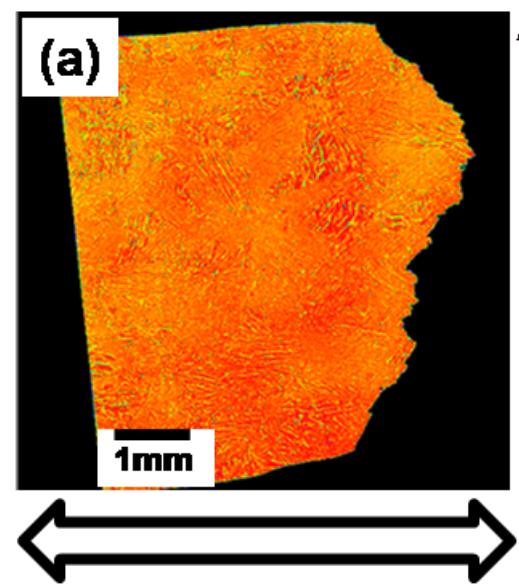

Longitudinal direction

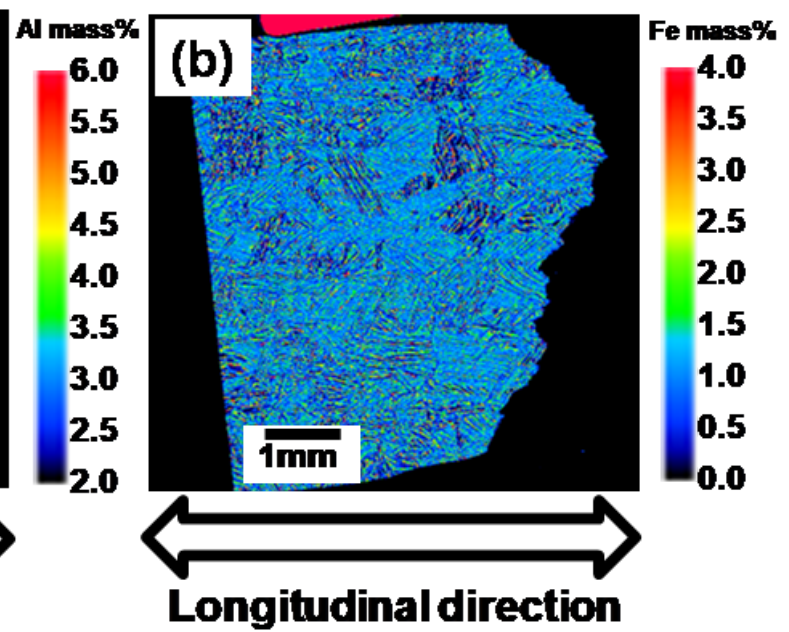

Longitudinal direction

Fig. 9 (a) Al and (b) Fe distributions in sintered Ti-5Al-1Fe bar manufactured using 5Al-1Fe-4Ti crushed-and-ground powders. EPMA analyses were conducted for fractured tensile test specimen taken from sintered cylindrical bar. 


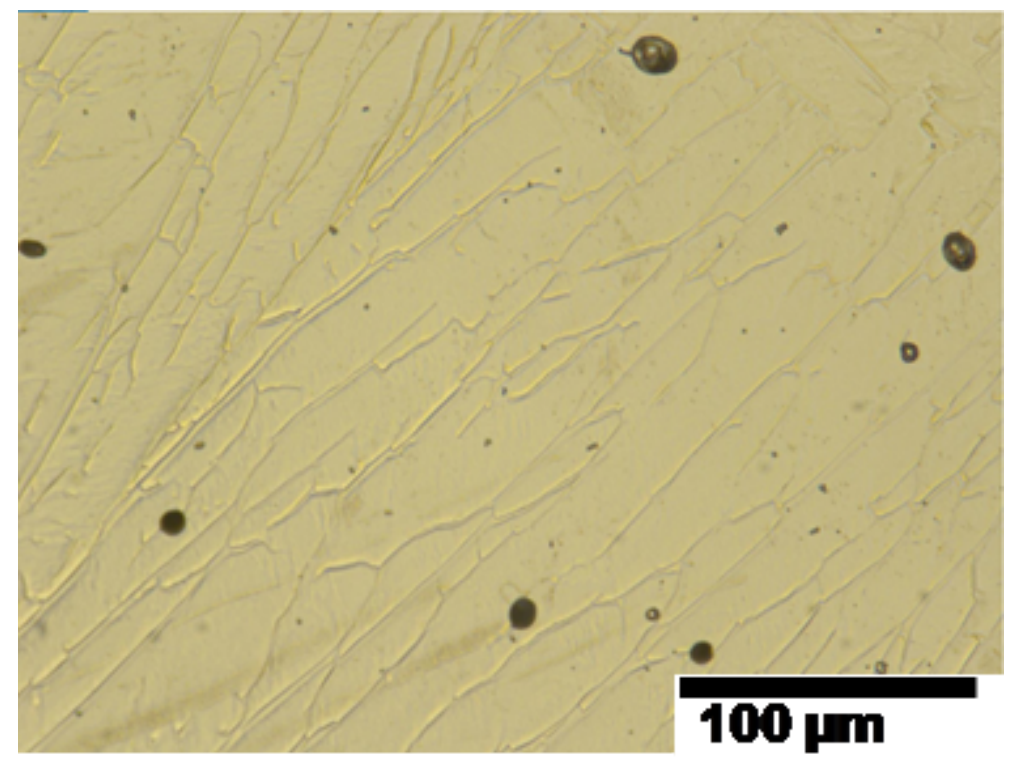

Fig.10 Optical micrograph of sintered Ti-5Al-1Fe bar manufactured using 5Al-1Fe-4Ti crushed-andground powders.

\section{Discussion}

According to the experimental results, there are two major differences between sintered specimens manufactured using 5Al-1Fe atomized powders and those manufactured using 5Al-1Fe-4Ti crushedand-ground powders

One is segregation of alloying elements, especially Al. In the sintered bar manufactured using atomized master alloy powders, strong segregation bands ranging from 3 to $5.5 \mathrm{mass} \%$ of $\mathrm{Al}$ were observed (Fig.7). As the Al concentrated and diluted layers are vertical to the longitudinal direction and extended horizontally, meaning that the segregation bands are created in the powder filling process. This thought is supported by the fact that alloying element contents were low at the top portion in this specimen (Table 3).

There are a lot of factors affecting segregation during powder filling, such as powder size, shape, density, etc. Among them, density of $5 \mathrm{Al}-1 \mathrm{Fe}$ atomized powders $\left(2.73 \mathrm{~g} / \mathrm{cm}^{3}\right)$ is considerably lower 
than $5 \mathrm{Al}-1 \mathrm{Fe}-4 \mathrm{Ti}$ crushed-and-ground powders $\left(3.72 \mathrm{~g} / \mathrm{cm}^{3}\right)$ and HDH titanium powders used (4.51 $\mathrm{g} / \mathrm{cm}^{3}$ ), indicating $5 \mathrm{Al}-1 \mathrm{Fe}$ powders are disadvantageous for obtaining homogeneous $\mathrm{Al}$ distribution when they are blended with Ti powders. Size of the atomized powders is large compared to Ti-5Al$4 \mathrm{Ti}$ crushed-and-ground powders (Tables 1 and 2). In this respect, 5Al-1Fe atomized powders are advantageous for preventing from intense segregation. However, both master alloys are finer than HDH titanium powders and the size advantage of the atomized powders may not be enjoyed. Shape of powder is also an important factor enhancing segregation. Spherical shape of the atomized powders should have extremely high flowability, which should act as a factor promoting segregation.

As results of the influence of those factors, it is considered that intense segregation occurred in the sintered Ti-5Al-1Fe specimen manufactured using 5Al-1Fe atomized powders.

The reason why Fe was homogeneously distributed in both specimens manufactured using the atomized powders and the crushed-and-ground powders is considered that Fe has considerably high diffusivity compared to $\mathrm{Al}$ and $\mathrm{Ti}$.

The other conspicuous difference between sintered specimens manufactured using 5Al-1Fe atomized powders and those manufactured using $5 \mathrm{Al}-1 \mathrm{Fe}-4 \mathrm{Ti}$ crushed-and-ground powders is sintered density.

As shown in Figs.8 and 10, the sintered bar specimen manufactured using 5Al-1Fe atomized powders contains a lot of relatively large pores, while there are a few tiny pores in the specimen manufactured using 5Al-1Fe-4Ti crushed-and-ground powders. The features of microstructures are clearly seen in density : Relative density of the former was $93.9 \%$ and that of the latter is $99.3 \%$. Powder size difference may partially affect the density of sintered specimen. In addition, emergence of liquid phase during sintering process may affect sintered density. As indicated in Fig.3, 5Al-1Fe atomized powders contain $\mathrm{Al}$ base alloy phase (probably containing some amount of $\mathrm{Fe}$ ) having low melting point. In fact, DTA analysis indicates the liquid phase emerged at $649{ }^{\circ} \mathrm{C}$. It is natural to think that the liquid phase emerged during heating to sintering temperature at $1250{ }^{\circ} \mathrm{C}$ and left fairly large pores, resulting in lower density. Here, it should be noted that fine pure $\mathrm{Al}$ powders are considered not to generate the liquid phase when blended with pure Ti powders and sintered in vacuum ${ }^{(11)}$ because aluminizing reaction preferentially occurs. As shown in Fig.2, Fe-Al intermetallics are contained in the powders and $\mathrm{Al}$ phase must contain some amount of $\mathrm{Fe}$, as described before. Fe may hinder the aluminizing of titanium powders and allow the liquid phase generation.

This phenomenon does not occur in 5Al-1Fe-4Ti crushed-and-ground powders because substances having low melting point are not contained in the powders as shown in Figs.5 and 6. 
By taking the above discussion into account, it is concluded that atomized powders, which are quite simple to be obtained, are not always beneficial to manufacture sintered titanium alloys by BE/PM. Phase constitutions, melting point of each phase and density have to be adjusted. Meanwhile, Ti-AlFe ternary master alloy powders manufactured by crushing and grinding melt ingots are advantageous to obtain homogeneous titanium alloy products by BE/PM.

\section{Conclusions}

From the viewpoints of homogeneity of $\mathrm{Al}$ and $\mathrm{Fe}$ in sintered Ti-5Al-1Fe manufactured by the blended elemental powder metallurgy (BE/PM), two master alloy powders, atomized spherical 5Al$1 \mathrm{Fe}$ and crushed-and-ground polyhedron $5 \mathrm{Al}-1 \mathrm{Fe}-4 \mathrm{Ti}$ ternary powders were investigated. Obtained results are as follows :

1. Intense segregation of $\mathrm{Al}$ is recognized in the sintered specimen manufactured using $5 \mathrm{Al}-$ $1 \mathrm{Fe}$ atomized powders, while strong segregation is not observed in the specimen manufactured using $5 \mathrm{Al}-1 \mathrm{Fe}-4 \mathrm{Ti}$ crushed-and-ground powders.

2. Density of sintered specimen manufactured using $5 \mathrm{Al}-1 \mathrm{Fe}$ atomized powders is lower than that manufactured using $5 \mathrm{Al}-1 \mathrm{Fe}-4 \mathrm{Ti}$ crushed-and-ground powders.

3. Intense Al segregation is probably caused by lower density of the substance and high flowability generated by spherical shape.

4. Liquid phase may emerge during sintering in 5Al-1Fe atomized powders, which may contribute to low density of the sintered specimen.

5. Although atomized powders are quite simple to be obtained, a lot of factors such as phase constitutions, melting points, density etc. have to be taken into account to manufacture sintered titanium alloys with high homogeneity by BE/PM. Meanwhile, Ti-Al-Fe ternary master alloy powders manufactured by crushing and grinding route are advantageous to obtain homogeneous titanium alloy products by BE/PM.

\section{References}

[1] H. Fujii and T.Maeda : NSSMC Tech. Rep., No.106, (2014), p.16. 
[2] H. Fujii : Titanium Jpn., 64, (2016) p. 125. (in Japanese)

[3] H. Fujii : J. Jpn. Soc. Tchnol. Plast, 56, (2015) p. 530. (in Japanese)

[4] H. Fujii : Bull. ISIJ, 15, (2010) p. 686. (in Japanese)

[5] H. Fujii and K. Fujisawa : Materia Jpn, 34, (1995), p. 218. (in Japanese)

[6] M. Hagiwara, Y. Kaieda, Y. Kawabe, S. Miura, T. Hirano and S. Nagasaki : Tetsu-to-Hagane, 77, (1991), p. 139. (in Japanese)

[7] H. Fujii, K. Fujisawa, K. Takahashi and T. Yamazaki : NSC Tech. Rep., No.85, (2001), p.77.

[8] H. Fujii, K. Takahashi : CAMP-ISIJ, Vol. 7, (1994), p. 1569. (in Japanese)

[9] M. Hayakawa, H. Fujii, M. Horikawa, Y. Inoue and M. Morita : CAMP-ISIJ, Vol. 32, (2019), p. 371. (in Japanese)

[10] Dogan C and Saritas S : International Journal of Powder Metallurgy, Vol. 30, (1994), p. 419-427.

[11] H. Sina, K. Babu Surreddi and S. Iyengar : J. Alloys Compd. 661(2016), p.294-305 